\title{
CONSIDERAÇÕES SOBRE O MÉTODO POR EXEMPLOS DE LUDWIG WITTGENSTEIN
}

\author{
Gustavo Augusto Fonseca Silva ${ }^{1}$ \\ Universidade Federal de Minas Gerais (UFMG) \\ (i) http://orcid.org/0000-0001-7427-4504 \\ E-mail: fonsecaugusto@hotmail.com
}

\section{RESUMO:}

Em sua segunda filosofia, Ludwig Wittgenstein apresenta um método por exemplos com o intuito de resolver de vez os problemas filosóficos. De acordo com Wittgenstein, em vez de buscar a essência definidora dos conceitos, como Sócrates demandava de seus interlocutores, caberia aos filósofos dar exemplos dos conceitos a fim de responder às questões tradicionais da filosofia, como “O que é o conhecimento?", “O que é a amizade?", “O que é o justo?”. Neste artigo, não apenas se argumenta que o método por exemplos de Wittgenstein nunca poderia resolver de vez os problemas filosóficos porque diferentes pessoas dão diferentes exemplos de um conceito, sendo impossível decidir objetivamente quais são os exemplos certos e quais são os exemplos errados, como se analisa o fato de que Wittgenstein desconsiderou esse empecilho ao sucesso de seu método ao elaborá-lo. Além disso, reitera-se neste texto o dever dos filósofos de buscar a essência definidora dos conceitos.

PALAVRAS-CHAVE: Ludwig Wittgenstein; Método por exemplos; Investigações filosóficas; Sócrates; Maiêutica.

\section{REMARKS ON LUDWIG WITTGENSTEIN'S METHOD BY EXAMPLES}

\begin{abstract}
:
In his second philosophy, Ludwig Wittgenstein offers a method by examples with intents of finally solving the philosophical problems. According to Wittgenstein, instead of searching for an essence that defines concepts, as Socrates demanded from his interlocutors, philosophers should show examples for concepts, thus responding to tradicional philosophical questions such as "What is knowledge?", "What is friendship?", "What is fair?". This article argues that Wittgenstein's method by examples could never solve for once philosophical problems, because people are different and, therefore, offer different examples for concepts, making it impossible to identify objectively the right and wrong examples. In addition, it analyses the fact that Wittgenstein disregarded such hindrance to the success of his method while formulating it. Furthermore, this work reiterates philosophers' duty to search for the essence defining concepts.
\end{abstract}

KEYWORDS: Ludwig Wittgenstein; Method by examples; Philosophical investigations; Socrates; Maieutics.

\footnotetext{
1 Doutorando na Universidade Federal de Minas Gerais (UFMG), Belo Horizonte - MG, Brasil.
}

SILVA, Gustavo Augusto Fonseca. Considerações sobre o método por exemplos de Ludwig Wittgenstein. Griot : Revista de Filosofia, Amargosa - BA, v.20, n.2, p.140-153, junho, 2020. 


\section{Introdução}

Após ter reconhecido, no fim dos anos 1920, que não havia de fato resolvido de vez os problemas filosóficos, como havia declarado no prefácio do Tractatus logico-philosophicus (1921), Ludwig Wittgenstein decide voltar para Cambridge, Inglaterra, a fim de se tornar efetivamente "o terminus ad quem da grande filosofia ocidental" (WITTGENSTEIN, 2010a, p. 58). Com esse intuito, e em franca oposição à concepção filosófica do Tractatus, Wittgenstein passa a defender no início dos anos 1930 que, em vez de ensinar doutrinas e desenvolver teorias, como ele havia feito em seu livro, caberia ao filósofo demonstrar uma técnica, um método para chegar à clareza (MONK, 1995, p. 271). Convencido de que dessa forma poderia realmente resolver de vez os problemas filosóficos, Wittgenstein declararia já em outubro de 1930, na aula inaugural de seu curso de filosofia na Universidade de Cambridge, que tinha obtido "uma concepção clara do método correto em filosofia" (ibid., p. 272): “O nimbo da filosofia se perdeu. Pois agora temos um método para fazer filosofia, e podemos falar de filósofos hábeis. Compare-se a diferença entre alquimia e química: a química possui um método e nós podemos falar de químicos hábeis" (ibid.).

No $§ 133$ das Investigações filosóficas, Wittgenstein apresenta de forma simples e direta o seu método para fazer filosofia, isto é, o seu método por exemplos:

[...] a clareza à qual aspiramos é na verdade uma clareza completa. Mas isto significa apenas que os problemas filosóficos devem desaparecer completamente.

A verdadeira descoberta é a que me torna capaz de romper com o filosofar, quando quiser. - A que acalma a filosofia, de tal modo que esta não seja mais fustigada por questões que colocam ela própria em questão. - Mostra-se agora, isto sim, um método por exemplos, e a série desses exemplos pode ser interrompida. - Resolvem-se problemas (afastam-se dificuldades), não um problema.

Wittgenstein “sustentou que seu 'novo método' de fazer filosofia constituiu uma 'guinada' no 'desenvolvimento do pensamento humano', comparável à revolução promovida por Galileu na ciência" (GLOCK, 1998, p. 163). Mais que isso: Wittgenstein sustentou que seu método por exemplos, que ele certa vez disse ser exatamente oposto ao de Sócrates (MONK, 1995, p. 305), levaria à clareza completa, com a qual ele acreditava que os problemas filosóficos desapareceriam completamente. Hoje, porém, quase 90 anos depois da declaração triunfal de Wittgenstein em sala de aula, parece evidente que ele não havia de fato obtido uma concepção clara do método correto em filosofia. Muito menos que o nimbo da filosofia havia se perdido. No entanto, ao fim do ensaio "Wittgenstein's use of examples", publicado no Oxford Handbook of Wittgenstein, Beth Savickey um tanto surpreendentemente afirma:

Exemplos oferecem clarificação de nossos conceitos em todas as suas variações. Esta é a verdadeira descoberta de Wittgenstein. A dificuldade não é de encontrar a solução, mas de reconhecer o uso de exemplos de Wittgenstein como a solução, não como algo preliminar a ela (p. 695). ${ }^{2}$

Considerando-se que o novo método de Wittgenstein de fazer filosofia não o levou realmente a resolver de vez os problemas filosóficos, é difícil, de um lado, reconhecer o seu uso de exemplos como a solução. Por outro lado, não é difícil reconhecer que o método por exemplos jamais poderia ser a solução pelo fato de que diferentes pessoas dão diferentes exemplos de um conceito, sem haver um modo de decidir objetivamente quais são os exemplos certos e quais são

2 As traduções das citações de obras não publicadas em português foram feitas pelo autor. 
os exemplos errados. Detalhar como Wittgenstein ignorou esse entrave a seu método por exemplos e reafirmar o método de Sócrates - isto é, a busca pela essência definidora dos conceitos - são os objetivos deste artigo.

\section{Uma autoridade externa}

Ao refletir sobre questões relativas ao bem e ao mal no oitavo capítulo de $O$ reino de Deus está em vós, LievTolstoi, um dos autores que Wittgenstein mais admirava (MONK, 1995, p. 115), observou que "nenhuma definição humana pode fazer que aquilo que uns consideram o mal seja considerado pelos demais como tal" (TOLSTOI, 2011, p. 72) e que "não há, nem pode haver, uma autoridade externa que dê uma definição do mal que seja reconhecida por todos" (ibid., p. 74). A mesma dificuldade, evidentemente, apresenta-se ao método por exemplos de Wittgenstein, já que também não há, nem pode haver, uma autoridade externa que dê exemplos do conceito de mal, assim como de qualquer outro conceito, que sejam reconhecidos por todos. Em uma aula de 1938, Rush Rhees apontou esse problema a Wittgenstein, que simplesmente o descartou como sem importância:

[Rhees fez a Wittgenstein uma pergunta sobre a sua 'teoria' da deterioração. ]

Pensam que tenho uma teoria? Pensam que estou a dizer aquilo que a deterioração é? Aquilo que faço é descrever diferentes coisas a que se chama deterioração. Poderia concordar com a deterioração - "A vossa bela cultura musical é ótima, mas estou muito contente que as crianças já não tenham de aprender harmonia." [Rhees: Será que aquilo que diz não implica uma preferência por certos modos de usar 'deterioração'?] Muito bem, se se quiser, mas isso, já agora - não, não tem importância. O meu exemplo de deterioração é um exemplo de uma coisa que conheço, talvez de uma coisa de que não gosto - não sei. 'Deterioração' aplica-se à pequena parte das coisas que é possível que eu saiba (WITTGENSTEIN, 2009b, p. 29-30).

Aquilo que Wittgenstein dizia implicava uma preferência por certos modos de usar "deterioração" e é claro que isso tem importância. O exemplo de deterioração de Wittgenstein é um exemplo de uma coisa que ele conhecia, talvez de uma coisa de que não gostava - não sei. "Deterioração" aplicava-se à pequena parte das coisas que é possível que ele soubesse. Mas também é possível que ele não soubesse. Um fato que Wittgenstein desconsiderou ao elaborar seu método por exemplos, assim como ao refletir sobre seguir regras. "Nosso uso da linguagem é como jogar um jogo de acordo com as regras" (WITTGENSTEIN, 2001, p. 32), disse Wittgenstein a seus alunos em mais uma aula do início dos anos 1930. Em certo sentido, é esse mesmo o caso, como aliás já havia afirmado Fritz Mauthner no monumental Beiträgezueiner Kritik der Sprache, que Wittgenstein conhecia desde a juventude (JANIK \& TOULMIN, 1991, p. 140). No entanto, as regras "sempre admitem interpretações divergentes" (PEARS, 1973, p. 171). Em especial as regras do uso da linguagem. Aparentemente sem considerar isso, Wittgenstein escreve no $§ 54$ das Investigações filosóficas:

Dizemos que se joga segundo esta ou aquela regra, porque um observador pode ler essas regras nas práxis do jogo [...]. - Mas como o observador distingue, nesse caso, entre um erro de quem joga e uma jogada certa? Há para isso indícios no comportamento dos jogadores.

Mas como o observador distingue, no uso das palavras "bem", "mal" e "deterioração", entre um erro de quem fala e um uso certo? Há para isso indícios no comportamento dos falantes? Além do mais, quem seria a autoridade externa que distinguiria, no uso dessas palavras, entre um erro de quem fala e um uso certo? E quem seria a autoridade externa que 
ensinaria às pessoas o uso certo das palavras "bem", "mal" e "deterioração" até a clareza completa? "Pois não pertence ao seguir uma regra a técnica (a possibilidade) de treinar o outro nela? E por meio de exemplos, ademais. E o critério de sua compreensão há de ser a coincidência das ações individuais [...]" (WITTGENSTEIN, 1987, VII, § 53). Portanto, quem usasse as palavras "bem", "mal" e "deterioração" sem coincidência com Wittgenstein não teria compreendido a regra? Quem usasse as palavras "bem", "mal" e "deterioração" sem coincidência com Wittgenstein cometeria um erro? Indiferente a dificuldades dessa natureza, Wittgenstein afirma no $§ 219$ das Investigações filosóficas: "Quando sigo a regra não escolho. Sigo a regra cegamente". De fato, quando sigo a regra de um jogo, não escolho. Sigo a regra cegamente. Mas que regra seguir cegamente no uso das palavras "bem", "mal" e "deterioração"? E que regra seguir cegamente no uso das demais palavras? Que regra seguir cegamente no uso da palavra "bom", por exemplo? "É bom porque Deus assim o ordenou” é a expressão correta para a ausência de fundamento" (WITTGENSTEIN, 2010a, p. 65), anotou Wittgenstein em seu diário no início dos anos 1930. Ateus como Friedrich Nietzsche e Bertrand Russell jamais seguiriam a mesma regra no uso da palavra "bom" - muito menos cegamente. Cometeriam, portanto, um erro?

Sem levar em conta que não há, nem pode haver, uma autoridade externa que dê exemplos dos conceitos que sejam reconhecidos por todos e que as regras do uso da linguagem sempre admitem interpretações divergentes, Wittgenstein convida no $§ 66$ das Investigações filosóficas:

\begin{abstract}
Considere, por exemplo, os processos que chamamos de "jogos". Refiro-me a jogos de tabuleiros, de cartas, de bola, torneios esportivos etc. $O$ que é comum a todos eles? Não diga: "Algo deve ser comum a eles, senão não se chamariam "jogos"”, - mas veja se algo é comum a eles todos. - Pois, se você os contempla, não verá na verdade algo que fosse comum a todos, mas verá semelhanças, parentescos, e até toda uma série deles. Como disse: não pense, mas veja! - Considere, por exemplo, os jogos de tabuleiro, com seus múltiplos parentescos. Agora passe para os jogos de carta: aqui você encontra muitas correspondências com aqueles da primeira classe, mas muitos traços comuns desaparecem e outros surgem. Se passarmos agora aos jogos de bola, muita coisa comum se conserva, mas muitas se perdem. - São todos "recreativos"? Compare o xadrez com o jogo da amarelinha. Ou há em todos um ganhar e um perder, ou uma concorrência entre os jogadores? Pense nas paciências. Nos jogos de bola há um ganhar e um perder; mas se uma criança atira a bola na parede e a apanha outra vez, este traço desapareceu. Veja que papéis desempenham a habilidade e a sorte. E como é diferente a habilidade no xadrez e no tênis. Pense agora nos brinquedos de roda: o elemento de divertimento está presente, mas quantos dos outros traços característicos desapareceram! E assim podemos percorrer muitos, muitos outros grupos de jogos e ver semelhanças surgirem e desaparecerem.
\end{abstract}

Considere agora o que chamamos de "ciência". Martin Heidegger, por exemplo, afirma em Ser e tempo (1927) que, "em geral, pode-se definir a ciência como o todo de um conjunto de fundamentação de proposições verdadeiras" (p. 47), mas logo admite: "Essa definição não é completa nem alcança o sentido de ciência". Em vista disso, Heidegger apresentaria outra definição desse conceito em um curso ministrado em 1929: "A ciência existe onde há institutos nos quais, com a ajuda do aparato técnico, são realizadas investigações" (HEIDEGGER, 2009, p. 44). No entanto, sabendo que essa nova definição também não é completa nem alcança o sentido de ciência, Heidegger prontamente observa, antecipando-se às "semelhanças de família" wittgensteinianas (WITTGENSTEIN, 2008, p. 45): 
Talvez esse enunciado seja válido para todas as ciências naturais e para a medicina, mas não para as ciências humanas. E como se dão as coisas em relação à ciência da música, que computamos às ciências históricas? Ela também possui institutos e até mesmo "instrumentos" como o cravo e o piano. Entretanto, esses instrumentos possuem uma função completamente diversa do que, por exemplo, um eletroscópio ou um termômetro. No fundo, porém, todas as ciências necessitam de instrumentos técnicos mesmo que sejam apenas livros. A ciência está impressa em livros. É certo que o livro possui na filologia uma função diversa do código civil na ciência do direito ou da bíblia na teologia. É questionável se com esse instrumento, com os livros - de qualquer modo não são todos os livros que se mostram como instrumentos -, a essência da ciência é caracterizada. Talvez se possa mesmo concluir a partir da essência da ciência que ela depende de uma tal técnica, de institutos, de livros, de aparatos etc. Todavia, a consequência da essência não se confunde com a própria essência, e, assim, indicar a concreção técnica na ciência pode ser muito essencial e, contudo, pode ser algo apenas extrínseco. Em contrapartida, exigimos uma determinação interna e talvez a encontremos ao perguntarmos para que serve todo esse dispositivo técnico (HEIDEGGER, 2009, p. 44).

Mais à frente, Heidegger retoma a discussão sobre o que é ciência e apresenta uma terceira definição desse conceito: "Ciência é conhecimento metódico, sistemático, exato e universalmente válido" (ibid., p. 45). Mas pondera:

Justamente os dois últimos predicados valem desde sempre como determinações insignes da ciência. As pessoas reportam-se frequentemente a Kant, que disse certa vez: "Afirmo, contudo, que em toda doutrina particular da natureza só se consegue encontrar tanta ciência propriamente dita quanto se puder encontrar aí matemática". Uma ciência só é científica na medida em que for matematizável. Dessa forma, as ciências humanas de modo algum são ciências, uma vez que se opõem por princípio à matematização. Por outro lado, a matemática se mostra como a ciência propriamente dita, pois é de fato a mais exata das ciências e seus resultados são, de modo puro e simples, universalmente válidos (ibid.).

Wittgenstein, por sua vez, seguindo regras diferentes das de Heidegger, não considerava a matemática uma ciência propriamente dita, mas sim uma série de técnicas, sem verdades a descobrir (WITTGENSTEIN, 2003, p. 297; MONK, 1995, p. 298). Mas a matemática, para Heidegger (2006, p. 45) "a ciência aparentemente mais rigorosa e de estrutura mais sólida", é uma ciência ou não? E o direito? E a teologia? E a história? E a música? E as ciências humanas são realmente científicas? Para responder a essas perguntas, é necessário responder à pergunta fundamental: o que é ciência? Uma pergunta intocada pelo método por exemplos. Uma pergunta que "foi frequentemente formulada pelos gregos. Ela é uma questão antiga, ou seja, uma questão sempre nova. Ela constitui uma daquelas questões que não se aquietam quando dela já temos à mão uma definição" (HEIDEGGER, 2009, p. 28). Além disso, ela constitui uma daquelas questões que não se aquietam quando dela só temos à mão exemplos. Sem perceber isso, Wittgenstein pergunta-se no $§ 69$ das Investigações filosóficas:

Como explicaríamos a alguém o que é um jogo? Creio que lhe descreveríamos jogos, e poderíamos acrescentar à descrição: "isto e outras coisas semelhantes chamamos de “jogos"”. E nós próprios sabemos mais? Será que apenas a outrem não podemos dizer exatamente o que é um jogo? - Mas isto não é ignorância. Não conhecemos os limites, porque nenhum está traçado.

E como explicaríamos a alguém o que é ciência? Creio que, seguindo o método wittgensteiniano, lhe descreveríamos exemplos, e poderíamos acrescentar à descrição: “isto $e$ 
outras coisas semelhantes chamamos de "ciência". Mas entre esses exemplos deveríamos incluir ou não a matemática? E o direito, a teologia, a história, a música e as ciências humanas? Sem enfrentar esse tipo de problema, Wittgenstein retoma no $§ 71$ das Investigações filosóficas a questão de como explicar o que é um jogo e afirma:

[...] exatamente assim explica-se o que é um jogo. Dão-se exemplos e quer-se que eles sejam compreendidos num certo sentido. - Mas com essa expressão não quero dizer que essa pessoa deva ver agora nesses exemplos o algo em comum que eu - por alguma razão - não posso exprimir. Mas sim que tal pessoa deva agora empregar esses exemplos de um determinado modo. A exemplificação não é aqui um meio indireto de elucidação, - na falta de outro melhor. Pois toda elucidação geral pode também ser mal compreendida. Eis como jogamos o jogo. (Refiro-me ao jogo de linguagem com a palavra "jogo".)

De acordo com Wittgenstein, exatamente assim explica-se o que é ciência. Dão-se exemplos e quer-se que eles sejam compreendidos num certo sentido e que se empreguem esses exemplos de um determinado modo. Wittgenstein, no entanto, desconsiderou o fato de que diferentes pessoas dão diferentes exemplos e os empregam de diferentes modos, sem haver uma autoridade externa que distinga entre um exemplo errado e um exemplo certo. Eis como jogamos o jogo. (Refiro-me ao jogo de linguagem com a palavra "ciência".)

Sem se deter, porém, nessas dificuldades, Wittgenstein estendeu seu novo método filosófico à estética. Assim, nos anos 1930, Wittgenstein passou a defender que, em vez de ensinar doutrinas e desenvolver teorias sobre o belo, caberia ao filósofo explicitar a beleza de uma obra de arte, explicando-a. Isto é, para Wittgenstein, em vez de teorias, é necessário "dar uma explicação que seja aceita. Este é o propósito da explicação" (MONK, 1995, p. 364). Mas quem poderia explicitar a beleza de uma obra de arte, explicando-a? Quem poderia dar uma explicação que fosse aceita? Julian Bell, aluno de Cambridge nos anos 1930, não teria a menor dúvida sobre quem Wittgenstein teria em mente, como ironizou neste poema sarcástico:

Pois [Wittgenstein] enuncia disparates, muitas afirmações faz,/ Sempre o seu voto de silêncio a quebrar;/ De ética, estética, fala dia e noite,/ E designa as coisas de boas ou más, ou certas e erradas./ [...]Quem, sobre qualquer assunto, já viu/ Ludwig refrear-se de estabelecer a lei?/ Em qualquer companhia ele grita e manda calar,/ Interrompe nossas frases e balbucia as suas;/ Discute sem cessar, severo, irado, vociferante,/ Certo de estar com a razão, e de estar certo orgulhoso,/ Tais defeitos são comuns, partilhados por todos em parte,/ Mas Wittgenstein pontifica sobre Arte (ibid., p. 237).

Certo de que seria a pessoa que daria uma explicação que fosse aceita, e de ser essa pessoa orgulhoso, Wittgenstein desconsiderou em estética que explicitar a beleza de uma obra de arte implica uma preferência e isso, evidentemente, tem importância. Musicalmente, por exemplo, a preferência de Wittgenstein restringia-se a seis compositores: Haydn, Mozart, Beethoven, Schubert, Brahms e Labor (ibid., p. 23). Obviamente, acreditar que alguma explicação da música de compositores que Wittgenstein detestava, como Mahler e Schönberg (ibid., p. 83), poderia convencê-lo é quase ridículo demais para pôr em palavras, já que "suas opiniões sobre a maioria dos assuntos era absoluta, não permitindo argumentos" (PASCAL, 1984, p. 17). Também é quase ridículo demais para pôr em palavras acreditar que uma explicação dos textos de Shakespeare, o "poeta dos poetas" (KIERKEGAARD, 2010, p. 56), poderia convencer Wittgenstein, que confessou: "Tenho uma profunda desconfiança perante a maior parte dos admiradores de Shakespeare" (WITTGENSTEIN, 1992, p. 123). Na verdade, Wittgenstein tinha uma profunda desconfiança perante a maior parte dos admiradores de muitos dos escritores mais prestigiados de seu tempo, como Rainer Maria Rilke e T. S. Eliot (BOUWSMA, 
2005, p. 118). Além disso, Wittgenstein tinha uma profunda desconfiança perante outras culturas que não a sua, a germânica; em especial, perante a cultura inglesa: "Acerca de um arquiteto ou músico (talvez de um artista em geral) inglês pode-se estar quase seguro de que se trata de um charlatão!", pontificou Wittgenstein (2010a, p. 73). Pior: ainda que abrisse certas exceções, como aos escritores russos Tolstoi e Dostoiévski, que ele tanto apreciava (cf., p. ex., MONK, 1995, p. 115, p. 132 e p. 482), Wittgenstein basicamente menosprezava o que não fosse de sua cultura ${ }^{3}$ :

A educação (aquisição da cultura) restitui a uma pessoa um bem que já lhe pertence. Com ela tal pessoa aprende, por assim dizer, a conhecer a herança paterna. Ao passo que outra pessoa assimila por meio dela formas cuja natureza lhe é estranha. E aí seria melhor se permanecesse inculta ainda que ficando repugnante \& tosca (WITTGENSTEIN, 2010a, p. 70-71).

O menosprezo de Wittgenstein por uma educação, por uma cultura que não fosse a sua alicerça seu método por exemplos, elaborado para explicar conceitos e proferir julgamentos sempre de seu ponto de vista, de sua cultura, de sua "forma de vida" (WITTGENSTEIN, 1999, $\S 23)$, nunca do ponto de vista do outro, da cultura do outro, da forma de vida do outro. "É como se disséssemos: "Classifico as obras de arte do seguinte modo: umas admiro, outras desprezo'. Este modo de classificação podia ser interessante" (WITTGENSTEIN, 2009b, p. 33). Sim, este modo de classificação podia ser interessante para alguém que "nunca se via pelos olhos dos outros" e "não tinha outros padrões a não ser os seus" (PASCAL, 1984, p. 47), mas evidentemente não resolve os problemas, nem afasta as dificuldades. ${ }^{4}$

\section{Para além da percepção comum do mundo: a perplexidade filosófica}

Além de ter passado a defender nos anos 1930 que, em vez de ensinar doutrinas e desenvolver teorias, caberia ao filósofo demonstrar uma técnica, um método para chegar à clareza, Wittgenstein começou a apregoar no mesmo período que "o filósofo é quem tem de curar em si mesmo muitas doenças do intelecto, antes de poder aceder às noções do senso comum" (WITTGENSTEIN, 1992, p. 70). Com essa convicção, Wittgenstein disse a seus alunos em uma aula de 1936:

Temos a sensação de que o homem comum, ao referir-se ao "bem" ou ao "número" etc., não sabe realmente o que está dizendo. Eu vejo algo de estranho na percepção e ele fala da percepção como se absolutamente não fosse estranha. Podemos afirmar que ele sabe o que está dizendo ou não?

Podemos afirmar ambas as coisas. Suponhamos duas pessoas jogando xadrez. Eu enxergo problemas estranhos quando examino as regras e as esmiúço. Mas Smith e Brown jogam xadrez sem dificuldade. Será que eles compreendem o jogo? Bem, eles estão jogando (MONK, 1995, p. 320).

Segundo Monk (ibid.), nas aulas desse ano, Wittgenstein recorrentemente defendeu, contra os filósofos, a percepção comum do mundo: "Quando um filósofo levanta dúvidas - sobre o tempo ou sobre estados mentais - que não ocorrem ao homem comum", explica-nos Monk a posição de Wittgenstein, "não é porque o filósofo tem mais discernimento que o homem comum

\footnotetext{
3 Para a discussão de outros aspectos contraditórios do pensamento wittgensteiniano, ver Silva (2018a, 2018b, 2018c, 2019a e 2019b).

4 Para uma "mudança de aspecto" quanto à postura egocêntrica de Wittgenstein à luz do diagnóstico póstumo de autismo, ver Silva (2019a).
} 
e sim porque, de certo modo, ele tem menos; o filósofo está sujeito à tentação de mal-entendidos que não ocorrem ao não filósofo". Realmente o filósofo está sujeito à tentação de mal-entendidos que não ocorrem ao não filósofo, porque o filósofo enxerga problemas estranhos quando examina as regras e as esmiúça. O já citado Heidegger, por exemplo, ao contrário do homem comum - "esse produto industrial que a natureza fabrica à razão de vários milhares por dia" (SCHOPENHAUER, 2011, § 36) -, viu o problema sobre o ser e por isso se perguntou pelo seu sentido:

O "ser" é o conceito evidente por si mesmo. Em todo conhecimento, enunciado ou relacionamento com os entes e em todo relacionar-se consigo mesmo, faz-se uso de "ser" e, nesse uso, compreende-se a palavra "sem mais". Todo mundo compreende: "o céu é azul", "eu sou feliz", etc. Mas essa compreensibilidade comum demonstra apenas a incompreensão (HEIDEGGER, 2006, p. 39).

Ciente de que a compreensibilidade comum demonstra apenas a incompreensão - ou seja, ciente de que "no âmbito dos conceitos fundamentais da filosofia, e até com relação ao conceito de 'ser', é um procedimento duvidoso recorrer à evidência, uma vez que o 'evidente', is to é, 'os juízos secretos da razão comum' (Kant), deve ser e permanecer o tema explícito da analítica ('o ofício dos filósofos")" (ibid., p. 39-40) -, Heidegger ressaltou que "se deve colocara questão do sentido de ser" (ibid., p. 40) a fim de ultrapassar a "compreensão vaga e mediana de ser" (ibid., p. 41).

Como Heidegger, Tolstoi podia enxergar e via o problema. Por isso, tampouco acedeu às noções do senso comum a fim de ultrapassar a compreensão vaga e mediana de arte:

O que é arte? Por que, até, fazer tal pergunta? Arte é arquitetura, escultura, pintura, música, poesia em todas as suas formas - essa é a resposta costumeira do homem comum, do amante da arte e mesmo do próprio artista, que supõe que aquilo de que ele está falando é entendido muito claramente e da mesma maneira por todas as pessoas. Mas na arquitetura, pode-se objetar, existem edifícios simples que não são obras de arte e edifícios que alegam ser obras de arte, mas são impróprios, feios, e portanto não podem ser considerados como tal. Qual é, então, o sinal de uma obra de arte? (TOLSTOI, 2002, p. 30).

Para o homem comum, observa Tolstoi mais à frente, o sinal de uma obra de arte é a beleza, sem incluir, no entanto, atividades como a do figurinista, perfumista, cabeleireiro e cozinheiro, ao contrário do que fazem especialistas como Renan, Kralik e Guyau, com os quais Tolstoi concorda (ibid., p. 32-34). Além disso, estando atento ao fato de que, "quanto mais vago e confuso o conceito expressado por uma palavra, maior a pose e segurança com que as pessoas a usam, fazendo de conta que o que se entende por essa palavra é tão simples e claro que nem vale a pena falar sobre o que ela realmente significa" (ibid., p. 34), Tolstoi alertou: "Milhares de eruditos a vêm discutindo por cento e cinquenta anos, e o significado da palavra beleza continua sendo um enigma" (ibid., p. 35). Tendo visto esse problema e mais uma vez se recusando a aceder às noções do senso comum a fim de ultrapassar a compreensão vaga e mediana de beleza, Tolstoi se perguntou:

O que, então, é esse estranho conceito de beleza, que parece tão compreensível para aqueles que não pensam sobre o que estão dizendo, enquanto que, por cento e cinquenta anos, filósofos de várias nações e das mais variadas tendências foram incapazes de concordar sobre sua definição? O que é esse conceito de beleza, sobre o qual se baseia a doutrina reinante da arte? (ibid.) 
Adiante, Tolstoi completa, antecipando-se às semelhanças de família de Wittgenstein:

Todas as tentativas de definir a beleza absoluta em si mesma - como imitação da natureza, como propósito, como correspondência de partes, simetria, harmonia, unidade na diversidade e assim por diante - ou não definem nada ou definem somente certas características de certas obras de arte, e estão longe de abranger tudo o que todas as pessoas sempre consideraram e ainda consideram ser arte (ibid., p. 64).

Assim, conclui Tolstoi, "uma definição objetiva da arte não existe", e as existentes são "uma e mesma definição subjetiva" (ibid., p. 65), baseada na ideia da "arte como manifestação da beleza, e da beleza como aquilo que agrada (sem suscitar desejo)". Contrário à ideia da beleza como o padrão do que é bom em arte (ibid., p. 89), Tolstoi abandona esse conceito em sua definição de arte, que para ele é "a atividade humana que consiste em um homem conscientemente transmitir a outros, por certos sinais exteriores, os sentimentos que ele vivenciou, e esses outros serem contagiados por esses sentimentos, experimentando-os também" (ibid., p. 76). Essa definição, claro, não é completa nem alcança o sentido de arte. Mas mais importante é observar que em sua pergunta sobre o sentido de beleza, não por coincidência, Tolstoi manifesta a mesma perplexidade de Santo Agostinho em sua famosa pergunta sobre o sentido de tempo, que Wittgenstein cita no §89 das Investigações filosóficas: "Que é, pois, o tempo? Se ninguém me pergunta, eu sei; se quero explicá-lo a quem me pede, não sei". Tampouco por coincidência, em sua pergunta sobre o sentido de ser, Heidegger manifesta a mesma perplexidade de Tolstoi em sua pergunta sobre o sentido de beleza e a mesma perplexidade de Agostinho em sua pergunta sobre o sentido de tempo, atestando que "para a filosofia só existe um começo: a perplexidade" (Teeteto, 155d).

Estando perplexos, os filósofos questionam o que parece evidente ao homem comum em busca dos "maiores conhecimentos, a saber, aqueles sobre a essência e o cerne das coisas" (NIETZSCHE, 2011, 3). Ignorando, porém, que "era natural que Sócrates indagasse a essência das coisas, pois tentava deduzir logicamente e o ponto de partida de toda elucidação lógica é a essência" (Metafísica, XIII, 4), Wittgenstein acreditava que essa busca filosófica tivesse se originado por influência do método científico:

O nosso desejo de generalidade tem uma outra fonte importante: a nossa preocupação com o método da ciência. Refiro-me ao método de reduzir a explicação a fenômenos naturais ao menor número possível de leis naturais primitivas e, na matemática, de unificação de diferentes tópicos por recurso a uma generalização. Os filósofos têm sempre presente o método da ciência e são irresistivelmente tentados a levantar questões e a responderem-nas do mesmo modo que a ciência. Esta tendência é a verdadeira fonte da metafísica, e leva o filósofo à total obscuridade (WITTGENSTEIN, 2008, p. 47).

Conforme Monk (1995, p. 305), para Wittgenstein "a busca da essência é um exemplo da ‘ânsia de generalidade' que brota do valor que atribuímos ao método da ciência”. Trata-se, é claro, de um erro esperado de alguém que se orgulhava não apenas de haver estudado pouca filosofia, mas de nunca ter lido uma palavra de Aristóteles (MONK, 1995, p. 438; DRURY, 1984, p. 158), desconhecendo, portanto, que "duas descobertas podem, com justiça, ser atribuídas a Sócrates: o raciocínio indutivo e a definição universal" e que "ambos estão associados ao ponto de partida da ciência" [archēn epistēmēs] (Metafísica, XIII, 4). Assim, a busca da essência em filosofia não se originou por influência da ciência. Pelo contrário: a busca da essência na ciência é que se originou por influência da filosofia. De fato, "o que a ciência é por sua parte reside na filosofia em um sentido originário. Filosofia é em verdade origem da ciência. [...] Na Antiguidade, a filosofia não recai no gênero das ciências. Ao contrário, são as ciências 
que se mostram aí como "filosofias' de um tipo determinado" (HEIDEGGER, 2009, p. 20). Ciente disso, Nietzsche afirma com razão que a ciência natural é tão somente "o mais novo dos métodos filosóficos" (NIETZSCHE, 2005, § 1) e que Sócrates é o progenitor da ciência (NIETZSCHE, 2007,§ 16). Dessa forma, a busca da essência, o nosso desejo de generalidade, não tem por fonte a nossa preocupação com o método da ciência, porque é anterior à própria ciência, como enfatizaram Nietzsche e Heidegger em conformidade com Aristóteles, que nos ensina ainda que "só há conhecimento de uma coisa quando conhecemos sua essência" (Metafísica, VII, 6). Wittgenstein, no entanto, jamais compreendeu a busca dos filósofos pelos maiores conhecimentos. Nem a arte maiêutica, chegando mesmo a distorcê-la:

A ideia de que para tornar claro o sentido de um termo geral era necessário descobrir o elemento comum a todas as suas aplicações estorvou a investigação filosófica, não só porque não conduziu a qualquer resultado, mas também porque levou a que os filósofos rejeitassem como irrelevantes os casos concretos, os únicos que poderiam tê-los ajudado a compreenderem o uso do termo geral. Quando Sócrates faz a pergunta "O que é o conhecimento?", ele nem sequer considera como uma resposta preliminar a enumeração de casos de conhecimento (WITTGENSTEIN, 2008, p. 49).

Ora, no Teeteto(145c-146d), Sócrates considera como uma resposta preliminar à pergunta “O que é o conhecimento?" a enumeração da geometria, astronomia, música, aritmética, sapataria e demais artes do artesão e carpintaria como casos de conhecimento, tendo tal resposta ilustrado o fato de que "em vários dos primeiros diálogos (platônicos) encontramos oradores que cometem um erro elementar, apesar de comum, quando se lhes pede que deem a definição de um termo. O que fazem, em vez disso, é dar exemplos do mesmo" (RUSSELL, 2013 , p. 102). Mas não adianta responder à pergunta sobre o que é o conhecimento como faz Teeteto. Também "não adianta responder à pergunta sobre o que é o sagrado como faz Eutífron" (ibid., p. 102):

O sagrado, diz Eutífron, é processar o ofensor da religião. Mas, efetivamente, isto não é uma definição. A declaração estabelece simplesmente que processar o ofensor é um ato sagrado. Pode haver outros. Quanto ao que é o sagrado, continuamos ignorando. É como se alguém a quem perguntassem o que é um filósofo respondesse que Sócrates é um filósofo (ibid., p. 102-103).

Pelo fato de Wittgenstein nunca ter compreendido a busca dos filósofos pelos maiores conhecimentos, nem a arte maiêutica, não espanta sua sensação de uma "tremenda perda de tempo" ao ler os diálogos socráticos (WITTGENSTEIN, 1992,p. 30):“Qual é o sentido destes argumentos que nada provam e nada clarificam?" (ibid.). Também não espanta que Wittgenstein não conseguisse entender a grandiosidade de Platão, como registrou $O$. $K$. Bouwsma (2005, p. 106):

Os argumentos de Platão! Os seus simulacros de discussões! A ironia socrática! O método socrático! Os argumentos eram maus, os simulacros de discussões demasiado óbvios, a ironia socrática de mau gosto [...]. Quanto ao método socrático nos diálogos, brilha pela ausência. Os interlocutores são ingênuos, nunca têm um argumento próprio, dizem "sim" e "não" conforme Sócrates entende que digam.

Tampouco espanta que Wittgenstein nunca tenha compreendido a grandiosidade de Sócrates, "o grão-mestre de todos os ironistas" (KIERKEGAARD, 2010, p. 122), como deixa entrever em diálogo com Maurice Drury: 
Intriga-me por que Sócrates é considerado um grande filósofo. Porque, quando Sócrates pergunta o significado de uma palavra e as pessoas dão a ele exemplos de como aquela palavra é usada, ele não se satisfaz e quer uma definição única. Mas, se alguém me mostra como uma palavra é usada e seus diferentes significados, é justamente esse tipo de resposta que eu quero (DRURY, 1984, p. 115).

Sem surpresa alguma, Wittgenstein tampouco compreendeu Hegel - que ele, a propósito, nunca leu (MONK, 2005, p. 13) - em sua busca pelos maiores conhecimentos: "Hegel me parece estar sempre querendo dizer que coisas que parecem diferentes são na realidade iguais. Enquanto que meu interesse é mostrar que coisas que parecem iguais são na realidade diferentes" (DRURY, 1984,p. 157).E Wittgenstein me parece estar querendo dizer algo óbvio: que coisas que parecem diferentes são na realidade diferentes. Esse fato é confirmado por Wittgenstein ter cogitado usar a frase do bispo Joseph Butler "Cada coisa é o que é, não outra coisa" como epígrafe das Investigações filosóficas (MONK, 1995, p. 401-402). Ora, é óbvio que cada coisa é o que é, não outra coisa, mas o que é preciso é, "em uma palavra, proceder de tal modo que se conheça e que se pense como diferente tudo o que é diferente, apesar de uma conformidade parcial, e como idêntico tudo o que é idêntico, apesar de uma diferença igualmente parcial, o todo conforme a finalidade e o ponto de vista que dominam em cada operação: eis a obra do juízo" (SCHOPENHAUER, 2011, § 14). Ou seja, "reconhecer o que é idêntico nos fenômenos diversos, e o que é diferente nos semelhantes, aqui está, Platão repetiu-o muitas vezes, uma condição para filosofar" (ibid., § 22). Mas os argumentos de Platão nada provaram e nada clarificaram a Wittgenstein, que, a fim de sintetizar sua posição, também cogitou usar como epígrafe das Investigações filosóficas a frase do Rei Lear: "Eu vou ensinar-lhes diferenças" (DRURY, 1984, p. 157). Ensinar diferenças, no entanto, seria trivial ao grande Sócrates, que evidentemente sabia que a geometria, a astronomia, a música, a aritmética, a sapataria e as demais artes do artesão e a carpintaria são diferentes atividades. Sócrates, porém, não sabia o que nos autoriza a chamar essas diferentes atividades da mesma maneira: conhecimento. Sócrates também sabia que a fome, a sede e similares são desejos, mas não sabia o que nos autoriza a chamá-las pelo mesmo nome, como argumentou com Protarco, sem nada provar e nada clarificar a Wittgenstein:

Sócrates - Não afirmávamos há pouco que fome, sede e similares são desejos?

Protarco- Decididamente o são.

Sócrates - Qual é o traço idêntico que temos em vista e que nos autoriza a chamar todas essas coisas, tão distintas, pelo mesmo nome?

Protarco- Por Zeus, Sócrates, talvez não seja fácil determiná-lo, embora seja necessário que o determinemos (Filebo, 34d-e).

Cientes de que não é fácil determinar o traço idêntico que temos em vista e que nos autoriza a chamar coisas distintas pelo mesmo nome, os filósofos querem é saber "se a definição é possível, ou seja, se a essência é cognoscível" (Analíticos posteriores, I, XXII). Além disso, cientes de que "todo conceito surge pela igualação do não igual" (NIETZSCHE, 2009, p. 34), os filósofos não perdem de vista que, "quando nos ocupamos de definições, passamos a maior parte de nosso tempo debatendo se as coisas são idênticas ou distintas" (Tópicos, I, V). Assim, quando nos ocupamos da definição de um conceito como arte, passamos a maior parte de nosso tempo debatendo, por exemplo, se as atividades do figurinista, do perfumista, do cabeleireiro e do cozinheiro se igualam às atividades do arquiteto, do escultor, do pintor, do compositor e do poeta, ou seja, passamos a maior parte de nosso tempo debatendo se todas essas atividades desiguais podem ser igualadas sob o conceito de arte, como defendiam Renan, Kralik, Guyau e Tolstoi. Para Wittgenstein, no entanto, essa questão certamente não teria importância, assim 
como a questão de incluir ou não entre as atividades artísticas o artesanato, que ele considerava uma "enorme verruga", uma "espécie particular de doença" (WITTGENSTEIN, 2009b, p. 25). Nem a questão recolocada por Tolstoi, "em meio à proteção da autêntica tradição" (HEIDEGGER, 2009, p. 22), sobre o sentido de arte. Uma questão antiga, ou seja, uma questão sempre nova. Uma daquelas questões que não se aquietam quando dela já temos à mão uma definição.

\section{Considerações finais}

Na aula inaugural de seu curso de filosofia de 1930, além de ter declarado que o nimbo da filosofia havia se perdido, Wittgenstein disse a seus alunos: "O que é a filosofia? Um questionamento sobre a essência do mundo? Nós queremos uma resposta definitiva, ou alguma descrição do mundo, verificável ou não" (WITTGENSTEIN, 1980, p.21). Ao se perguntar sobre o que é a filosofia, Wittgenstein queria uma resposta definitiva, assim como queria um método filosófico definitivo, que resolveria de vez os problemas. Em sua ânsia de se tornar "o terminus ad quem da grande filosofia ocidental", porém, Wittgenstein ignorava que as "questões filosóficas [...] jamais poderão ser, em princípio, resolvidas no sentido de as podermos, algum dia, extinguir" (HEIDEGGER, 1994, p. 68). Não por acaso, Wittgenstein escreveu já no fim da vida: "Aqui gostaria de fazer uma observação genérica sobre a natureza dos problemas filosóficos. A falta de clareza filosófica é aflitiva. Ela será / sentida como vergonhosa. // como uma vergonha [...]" (WITTGENSTEIN, 2009a, III, § 33). Essa aflição, essa vergonha marcam o trabalho de Wittgenstein "no objeto mais difícil, abstruso, quase inalcançável do pensamento as tarefas da filosofia" (NIETZSCHE, 2011, 7). Tarefas que são intocadas pelo método por exemplos. Em vista disso, não surpreende que o próprio Wittgenstein jamais tenha empregado seu novo método em sua busca por respostas às "preocupações éticas e espirituais que dominaram sua vida" (MONK, 1995, p. 16). Tampouco surpreende que a técnica de Wittgenstein não tenha realmente lhe garantido "um lugar de verdadeiro repouso", como ele afirmou ter encontrado no início dos anos 1930 (ibid., p. 271). Muito menos surpreende que seu novo método filosófico não tenha lhe permitido de fato afastar as dificuldades, como ele admitiu a Rhees anos depois de ter proclamado que o nimbo da filosofia havia se perdido: "Você sabe que eu disse que eu posso parar de fazer filosofia quando eu quero. Isto é uma mentira. Eu não posso" (RHEES, 1984, p. 219, n. 7). 


\section{Referências}

ARISTÓTELES. Metafísica. 2. ed. São Paulo: Edipro, 2012.

ARISTÓTELES. Órganon: Categorias, Da interpretação, Analíticos anteriores, Analíticos posteriores, Tópicos, Refutações sofísticas.2. ed. São Paulo: Edipro, 2010.

BOUWSMA, OetsKolk. Conversas com Wittgenstein. Lisboa: Relógio D’Água Editores, 2005.

DRURY, Maurice O’C. Conversations with Wittgenstein. In: RHEES, Rush (Ed.). Recollections of Wittgenstein: Hermine Wittgenstein; Fania Pascal; Frank R. Leavis; John King; Maurice O'C. Drury. Oxford: Oxford University Press, p. 97-171, 1984.

GLOCK, Hans-Johann. Dicionário Wittgenstein.Rio de Janeiro: Jorge Zahar, 1998.

HEIDEGGER, Martin. Introdução à filosofia. São Paulo: Martins Fontes, 2009.

HEIDEGGER, Martin. Introdução à metafísica.4. ed. Rio de Janeiro: Tempo Brasileiro, 1994.

HEIDEGGER, Martin. Ser e tempo. 6. ed. Petrópolis: Editora Vozes; Bragança Paulista: Editora Universitária São Francisco, 2006.

JANIK, Allan; TOULMIN, Stephen. A Viena de Wittgenstein. Rio de Janeiro: Editora Campus, 1991.

KIERKEGAARD, Søren. O desespero humano: (doença até a morte). São Paulo: Editora Unesp, 2010.

KUUSELA, Oskari; MCGINN, Marie (Ed.). The Oxford Handbook of Wittgenstein. Oxford: Oxford University Press, 2014.

MONK, Ray. How to read Wittgenstein. Nova York: Norton, 2005.

MONK, Ray. Wittgenstein: o dever do gênio. São Paulo: Companhia das Letras, 1995.

NIETZSCHE, Friedrich. A filosofia na era trágica dos gregos. Porto Alegre: L\&PM Pocket, 2011.

NIETZSCHE, Friedrich. Humano, demasiado humano: um livro para espíritos livres. São Paulo: Companhia das Letras, 2005.

NIETZSCHE, Friedrich. O nascimento da tragédia: ou helenismo e pessimismo. São Paulo: Companhia das Letras, 2007.

NIETZSCHE, Friedrich. Sobre verdade e mentira. São Paulo: Hedra, 2009.

PASCAL, Fania. Wittgenstein: a personal memoir. In: RHEES, Rush (Ed.). Recollections of Wittgenstein: Hermine Wittgenstein; Fania Pascal; Frank R. Leavis; John King; Maurice O'C. Drury. Oxford: Oxford University Press, p. 12-49, 1984.

PEARS, David Francis. As ideias de Wittgenstein.São Paulo: Cultrix: Ed. Universidade de São Paulo, 1973.

PLATÃo. Diálogos I: Teeteto (ou do conhecimento); Sofista (ou do ser); Protágoras (ou sofistas). Bauru: Edipro, 2007.

PLATÃo. Diálogos IV: Parmênides (ou das Formas); Político (ou da realeza); Filebo (ou do prazer); Lísis (ou da amizade). Bauru: Edipro, 2009.

RHEES, Rush (Ed.). Recollections of Wittgenstein: Hermine Wittgenstein; Fania Pascal; Frank R. Leavis; John King; Maurice O'C. Drury. Oxford: Oxford University Press, 1984.

RUSSELL, Bertrand. História do pensamento ocidental: a aventura dos pré-socráticos a Wittgenstein. Rio de Janeiro: Nova Fronteira, 2013.

RUSSELL, Bertrand. Os problemas da filosofia. 3. ed. Coimbra: Armênio Amado, 1974.

SAVICKEY, Beth. Wittgenstein's use of examples. In: KUUSELA, Oskari; MCGINN, Marie (Ed.). The Oxford Handbook of Wittgenstein. Oxford: Oxford University Press, 2014, p. 667-695.

SCHOPENHAUER, Arthur.O mundo como vontade e representação. Rio de Janeiro: Contraponto, 2011.

SILVA, Gustavo A. F. A filosofia de Ludwig Wittgenstein à luz do diagnóstico de autismo. Griot: Revista de Filosofia, v. 19, n. 1, p. 226-253, 2019a. 
SILVA, Gustavo A. F. Observações sobre a filosofia da matemática de Ludwig Wittgenstein. Griot: Revista de Filosofia, v. 17, n. 1, p. 97-113, 2018a.

SILVA, Gustavo A. F. Observações sobre a filosofia da mente de Ludwig Wittgenstein. Problemata, v. 9, n. 4, p. 218-233, 2018b.

SILVA, Gustavo A. F. Observações sobre a meta final do modo de fazer filosofia de Ludwig Wittgenstein. Principia, v. 22, n. 3, p. 411-438, 2018 c.

SILVA, Gustavo A. F. Wittgenstein além dos limites da linguagem. Reflexões, v. 14, n. 1, p. 130$146,2019 \mathrm{~b}$.

TOLSTOI, Liev. O que é arte?: a polêmica visão do autor de Guerra e paz. Tradução Bete Torii. São Paulo: Ediouro, 2002.

TOLSTOI, Liev. Os últimos dias. São Paulo: Penguin Classics Companhia das Letras, 2011.

WITTGENSTEIN, Ludwig. Anotações sobre as cores. Campinas: Editora da Unicamp, 2009a.

WITTGENSTEIN, Ludwig. Aulas e conversas sobre estética, psicologia e fé religiosa. Lisboa: Cotovia, 2009b.

WITTGENSTEIN, Ludwig. Cultura e valor. Lisboa: Edições 70, 1992.

WITTGENSTEIN, Ludwig. Gramática filosófica. São Paulo: Loyola, 2003.

WITTGENSTEIN, Ludwig. Investigações filosóficas. São Paulo: Abril Cultural, 1999. (Coleção: Os pensadores).

WITTGENSTEIN, Ludwig. Movimentos de pensamento: diários de 1930-32/1936-37. São Paulo: Martins Fontes, 2010a.

WITTGENSTEIN, Ludwig. Observaciones sobre los fundamentos de la matemática. Madri: Alianza Editorial, 1987.

WITTGENSTEIN, Ludwig. O livro azul. Lisboa: Edições 70, 2008.

WITTGENSTEIN, Ludwig. Tractatuslogico-philosophicus. São Paulo: Edusp, 2010 b.

WITTGENSTEIN, Ludwig. Wittgenstein's lectures. Cambridge, 1930-1932: from the notes of John King and Desmond Lee. Lee, Desmond (Ed.). Totowa: Rowman and Littlefield, 1980.

WITTGENSTEIN, Ludwig. Wittgenstein's lectures: Cambridge, 1932-1935. Ambrose, Alice; Macdonald, Margaret (Ed.). Amherst, N.Y.: Prometheus Books, 2001.

Autor(a) para correspondência: Gustavo Augusto Fonseca Silva, Av. Antônio Carlos, 6627, Pampulha, 31270-901T, Belo Horizonte - MG, Brasil. fonsecaugusto@hotmail.com 